\title{
Fotografía de prensa y redes sociales: la técnica de Eye Tracking
}

institucional.us.es/ambitos/

\author{
Víctor Arrazola \\ Universitat de Barcelona \\ varrazal7@alumnes.ub.edu \\ Mari-Carmen Marcos \\ Universitat Pompeu Fabra \\ mcarmen.marcos@upf.edu
}

English Version: Press and social networks photography: the Eye Tracking technology

\begin{abstract}
Resumen
El artículo presenta la técnica del seguimiento de la mirada (eye tracking) y analizalos estudios previos que, basándose en esta técnica, se han realizado sobre la prensa en las redes sociales, con especial detenimiento en Facebook. El artículo también hace un recorrido por el papel de la imagen en la prensadesde los inicios del fotoperiodismo hasta la aparición del periodismo digital.Dela revisión bibliográfica realizada se desprende que existe un claro vacío de investigaciones que aborden un análisis conjunto de las imágenes y las redes socialeshaciendo uso de la técnica del seguimiento de la mirada.
\end{abstract}

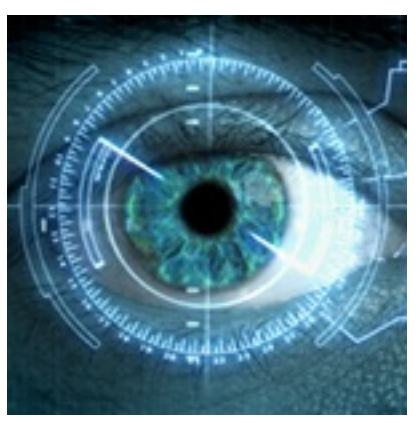

\section{Palabras clave}

Prensa, Fotografía, Redes sociales, Eye tracking.

\begin{abstract}
The article introduces the eye tracking technology and analyzes the previous studies conducted using this technology on press in social networks with a special focus on Facebook. It studies the role of image in press from the first steps of photojournalism to the dawn of online journalism. From the revised literature it can be observed a clear lack of research analyzing both the images and the social networks through eye tracking technology.
\end{abstract}

\section{Keywords}

Press, Photography, Social networks, Eye tracking.

\section{INTRODUCCIÓN}

Han pasado muchos años desde que en 1880 viera la luz la primera fotografía publicada en prensa en el New York Daily. Desde aquella primera incursión en el mundo periodístico, el papel de la imagen ha ido cambiando hasta convertirse en un género propio del sector, conocido como fotoperiodismo. Esta evolución constante de la fotografía se ha encontrado, irremediablemente, con la irrupción de las redes sociales, espacios que han sido aprovechados por los medios de comunicación para dar a conocer sus contenidos entre el público. A pesar de que ambos sujetos han sido ampliamente estudiados por separado nos encontramos con un vacío claro puesto que pocas investigaciones aúnan en su análisis imágenes y redes sociales.

Una de las técnicas de investigación más interesantes para analizar el comportamiento de la mirada de las personas al observar e interactuar con la información es la del seguimiento de la mirada o eye tracking. Por medio de la grabación del movimiento ocular se pueden obtener datos muy exactos de la mirada que son un claro indicador de la atención de las personas. Esta técnica se ha aplicado al estudio de las imágenes, al de la 
prensa y al de las redes sociales, pero en cambio no existe apenas bibliografía que cubra los tres campos al mismo tiempo: la imagen de prensa y su impacto en las redes sociales.

En este artículo analizamos los estudios previos que se han realizado sobre la prensa en las redes sociales, con especial detenimiento en Facebook, así como el papel de la imagen en la prensa, desde los inicios del fotoperiodismo hasta la irrupción del periodismo digital, para terminar con una mención a los avances realizados con la técnica de eye tracking.

\section{LA PERCEPCIÓN VISUAL DE LA IMAGEN}

\subsection{La tecnología de seguimiento de la mirada (eye tracking)}

El eye trackeres un dispositivo que detecta, sigue y graba los movimientos que los usuarios realizan con los ojos, la duración de la mirada y la dilatación de la pupila. La posibilidad de relacionar estas medidas con la atención hace del eye tracker una herramienta llena de utilidad para estudios de lectura, comportamiento e interacción entre las personas y las interfaces (figura 1).

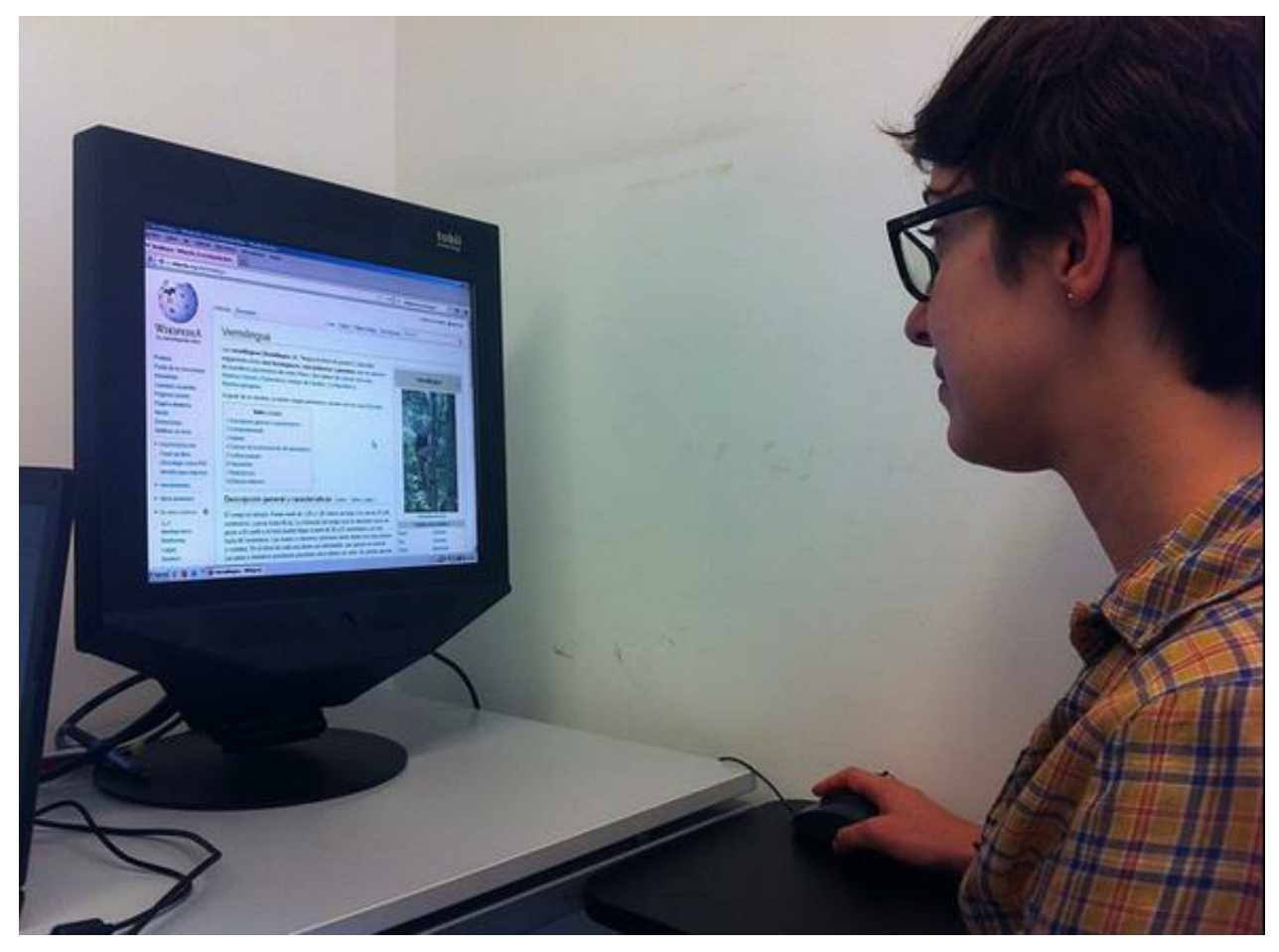

Figura 1. Un usuario realiza un test con un dispositivo de eye tracking.

Para realizar el seguimiento ocular, los eye trackers modernos funcionan de manera remota, es decir, sin intervenir de forma directa en los ojos de las personas. A día de hoy, la técnica más utilizada es la Pupil Centre Corneal Reflection (PCCR). Para aplicarla, el aparato incorpora una luz infrarroja y una cámara de vídeo.

Cuando está activado, el dispositivo ilumina al usuario con dos proyecciones de rayos infrarrojos que generan un reflejo en las córneas de los ojos, concretamente en la fóvea, que es una pequeña zona de la retina donde registramos la visión más nítida. Una cámara de vídeo integrada en el sistema recoge los reflejos junto con la posición del usuario y, a través de un procesamiento digital de la imagen, se determina la ubicación de las pupilas en un ratio de $50 \mathrm{~Hz}$ o superior. Después, la posición de las pupilas se mapea con la ubicación de la mirada en la pantalla y, de esta forma, se puede saber dónde tiene el usuario puesta su mirada -y por ende su atención, en cada momento de la grabación.

Tras la grabaciónde la mirada del usuario, el software asociado al eye tracker calcula una serie de métricas sobre su comportamiento visual. Si varios usuarios realizan un mismo test, se pueden obtener métricas conjuntas del grupo de usuario y detectar patrones de mirada. Estas son las métricas más utilizadas en estudios con eye tracking:

- Time tofirst fixation (TFF): tiempo que tarda el usuario en fijar su mirada por vez primera en una determinada zona de la pantalla objeto de estudio (llamada AOI, del inglés area of interest). 
- Fixations before (FB): número de fijaciones de la vista que ha habido desde que se ha presentado el estímulo en la pantalla hasta que el usuario ha llegado al AOI objeto de estudio.

- First fixation duration (FFD): duración de la primera fijación ocular en el AOI objeto de estudio.

- Fixation duration (FD): duración de cada una de las fijaciones en el AOI objeto de estudio.

- Total fixation duration (TFD): tiempo total que el usuario ha dedicado a mirar el AOI objeto de estudio.

- Fixation count (FC): número de fijaciones oculares en un AOI determinado.

- Visit duration (VD): tiempo que duran las miradas en el AOI objeto de estudio cada vez que un usuario dirige a ella su atención.

- Total visit duration (TVD): tiempo total que el usuario ha estado mirando el AOI objeto de estudio a lo largo de la sesión de grabación.

- Visit count (VC): número de veces que la mirada se ha dirigido al AOI objeto de estudio.

- Percentagefixated (\% Fix): porcentaje de usuarios que ha mirado el AOI objeto de estudio.

- Percentageclicked (\% Click): porcentaje de usuarios que ha clicado el AOI objeto de estudio.

- Time from first fixationto next mouse click (TFFC): tiempo que pasa desde que una persona mira por primera vez el AOI objeto de estudio hasta que clica en ella.

- Time to first mouse click (TFC): indica el tiempo que pasa desde que una persona es expuesta a un estímulo hasta que hasta que hace el primer clic.

- Mouse click count (MCC): número total de clics que ha recibido el AOI objeto de estudio.

La forma en que el software de análisis presenta los datos depende de la configuración que se le dé, pero en términos generales suelen usarse dos formatos: las tablas de datos donde se recogen las métricas para cada usuario y cada $\mathrm{AOI}$, y los mapas, donde de forma visual en unos casos se presenta el recorrido visual de un usuario (gazeplot) y en otros casos se muestran las zonas donde ha permanecido durante más tiempo su mirada (heatmap).

\subsection{Estudios de eye tracking sobre imágenes}

A pesar de que en los inicios de internet el texto prevalecía sobre lo audiovisual, con el paso del tiempo se ha acabado por implantar un modelo de web en el que el contenido multimedia, sea imagen, audio o vídeo, tienen una importancia capital.

Nielsen y Pernice (2010), en su libro sobre eye tracking aplicado a estudios de usabilidad, presentan resultados de diversos estudios realizados con esta técnica; el capítulo 6 está específicamente dedicado a mostrar los resultados obtenidos para estudios en los que el objeto estudiado era la imagen. De las cuatro posibles maneras de comunicarse a través de Internet (texto, imagen, sonido y vídeo) Nielsen y Pernice apuntan que la imagen es la más poderosa de todas. Para afirmarlo se basan en que la respuesta de los usuarios ante ese tipo de recurso es inmediata y apenas necesita de algunas fijaciones visuales para ser captada.

No obstante, en el estudio también se destaca la influencia que tiene sobre el comportamiento del usuario el tipo de imagen que se utiliza. Así pues, cuando se utilizan imágenes creativas o con un alto contenido emocional o explicativo la gente tiende a responder positivamente ante ellas. Sin embargo, esta respuesta se convierte en nula cuando a los usuarios se les presentan imágenes genéricas o que carecen de sentido alguno dentro del contexto de la página web. Cuando eso ocurre, los usuarios obvian la imagen (figura 2). 


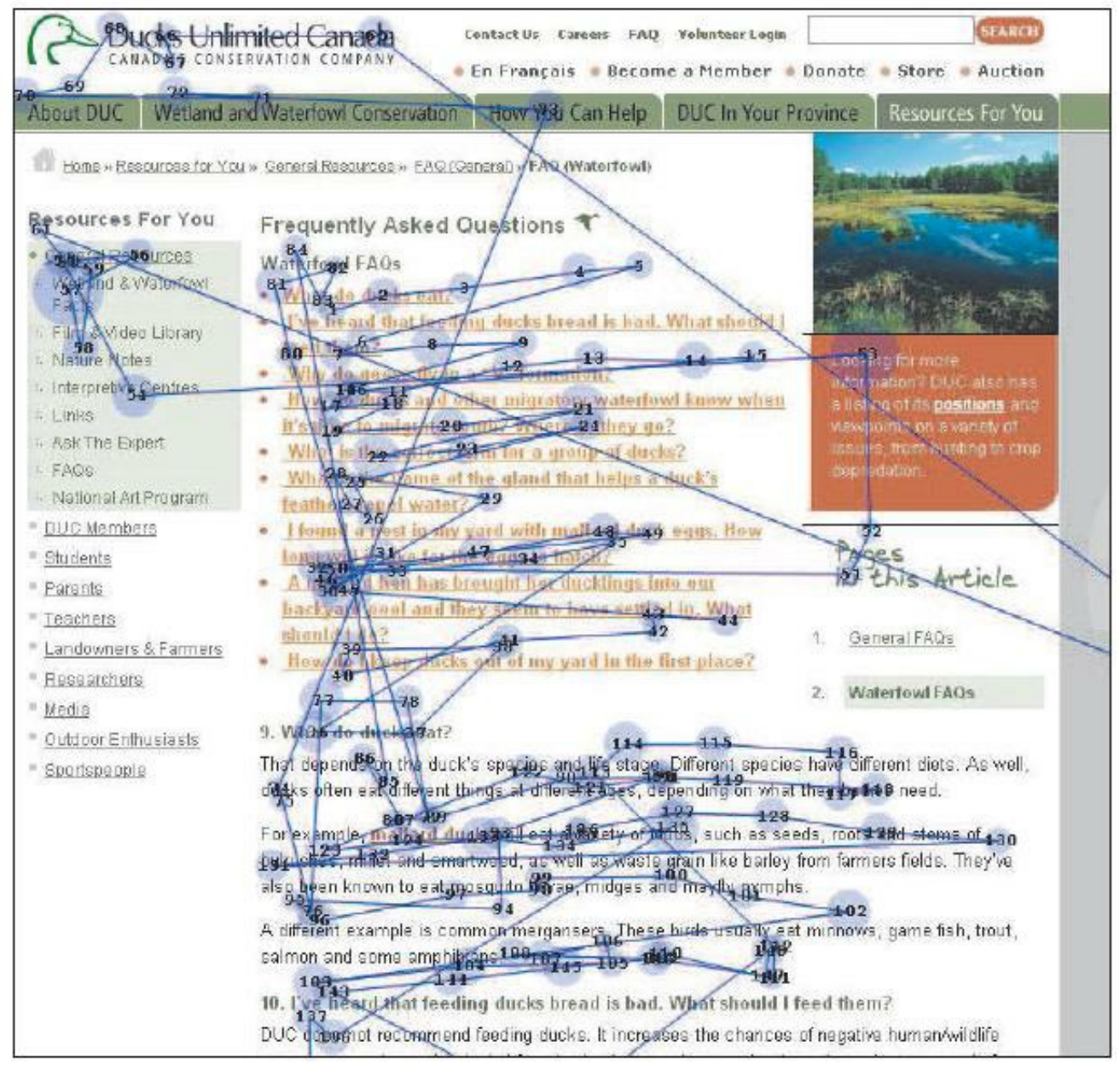

Figura 2. Mapa de recorrido (gazeplot) que muestran cómo los usuarios obvian las imágenes genéricas y poco creativas (Fuente: Nielsen y Pernice, 2010)

Según los resultados, las imágenes que más miran los usuarios son las que cuentan con las siguientes características: tienen un gran contraste y son de alta calidad, son recortadas y no reducidas cuando deben encajar en un espacio más pequeño, son fáciles de interpretar y evitan los detalles excesivos, están altamente relacionadas con el contenido de la página y son altamente atrayentes. A su vez, las imágenes atrayentes o con cierto magnetismo para captar la atención de los usuarios se caracterizan por contener rostros cercanos y sonrientes, personas mirando a la cámara, cuerpos atractivos, alimentos apetitosos e instrucciones precisas.

Por su parte, las imágenes que los usuarios ignoran son aquellas que tienen un bajo contraste y calidad, que están demasiado ocupadas, las que se asemejan a anuncios, aquellas que no están relacionadas con el contenido de la página, aquellas en que salen personas u objetos genéricos, las que son aburridas y las que son frías o demasiado pulidas (figura 3). 


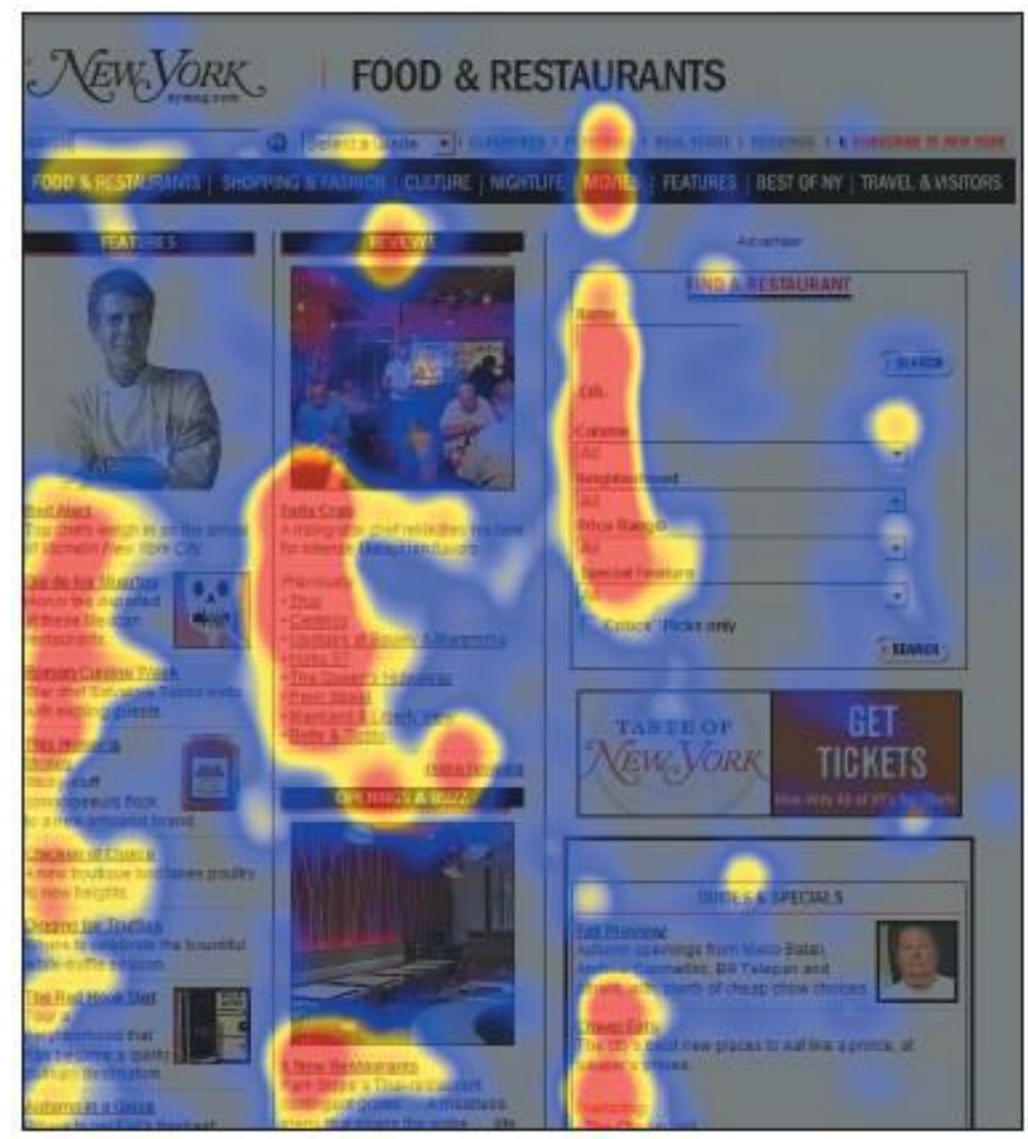

Figura 3.Mapa de calor ( heatmap) que muestra cómo los usuarios ignoran las imágenes con personas u objetos genéricos (Fuente: Nielsen y Pernice, 2010)

Estos resultados, que pueden ser aplicados al mundo de la prensa online, son una clara muestra de lo habituados que están los usuarios a lidiar con imágenes en la red.

Sin embargo, aun reuniendo estas características que destacan Nielsen y Pernice (2010), no todas las fotografías tienen el mismo poder de atracción. Es aquí donde entra en juego el tamaño, factor capital para que una imagen pueda llamar la atención del usuario.Un estudio previo del Poynterlnstitute (Outing, Ruel, 2004), indicaba que el tamaño de las imágenes tiene una gran influencia en la capacidad de atracción y atención por parte de los usuarios. Para llevar a cabo la investigación, se realizó un test de usuarios con 46 participantes. Durante una hora los usuarios navegaron por diferentes portales web de noticias ficticios generados por los propios investigadores. Los resultados revelaron que las imágenes de tamaño medio ( $210 \times 230$ píxeles) fueron vistas por el $70 \%$ de los participantes, mientras que las imágenes que tenían un tamaño similar al de una foto de carné sólo fueron visionadas por el $10 \%$ de los usuarios. Además, también se concluyó que las imágenes con rostros claros y limpios atraían a un mayor número de usuarios.

En la misma línea de investigación, tres años después Beymer, Orton y Russell (2007) llevaron a cabo un experimento para determinar si el tamaño de la imagen y la presencia de esta afectaban en el comportamiento de los usuarios a la hora de leer en Internet. Para el estudio, se realizó un test de usuarios de 82 personas y se utilizó un dispositivo de eye tracking. Los usuarios debían leer un mismo texto para las tres versiones de la página, lo único que cambiaba entre las versiones eran las fotografías. En la versión A aparecían dos fotografías relacionadas con el texto, en la versión B aparecían dos anuncios de empresas de la misma temática que el artículo y en la versión $\mathrm{C}$ no se mostraban fotografías ni anuncios. La investigación concluyó que aquellos usuarios a los que se mostró la versión A leían más despacio, justificando este detenimiento en el esfuerzo cognitivo que debía hacer el lector para relacionar las imágenes con el contenido. Además, se apreció que los usuarios que leían la versión B releían más el artículo, aduciendo que los anuncios distraían a los usuarios en sus lecturas online.

De los estudios presentados se concluye que la incorporación de imágenes a las páginas web influye en el comportamiento visual de los usuarios, y en la atención que ponen en la lectura, y que ese comportamiento 
varía en función del contenido de la imagen, su tamaño y la relación que guarda con el texto al que acompaña. Estos resultados son de sumo interés para la fotografía de prensa, a lo cual dedicamos el siguiente apartado.

\section{LA FOTOGRAFÍA EN LA PRENSA}

\subsection{Del papel a lo digital}

Aunque ya habían aparecido con anterioridad algunas imágenes en la prensa, fue el 4 de marzo de 1880 cuando apareció por vez primera en un periódico una fotografía reproducida con medios puramente mecánicos (figura 4). La imagen vio la luz en el Daily Herald neoyorquino gracias a una técnica conocida como el Halftone (de la que finalmente resultó la tipografía), que consistía en reproducir una fotografía a través de una pantalla tramada que la dividía en una multitud de puntos. La aparición de la imagen en la prensa supuso un cambio radical en la comunicación de masas. A partir de ese momento los lectores empezaron a poner cara a los personajes públicos y a poder ver imágenes de los acontecimientos y eventos que se llevaban a cabo en todo el mundo. Más tarde llegarían las imágenes en color y nuevas técnicas que perfeccionarían la impresión y mejorarían la nitidez de las fotografías.

Figura 4. Primera fotografía publicada en un periódico New York DailyHeraldel4 de marzo de 1880

La llegada de internet es, desde la aparición de la fotografía, el mayor desafío que ha tenido que afrontar el mundo del periodismo en su historia reciente. La aparición de la prensa online ha supuesto grandes cambios en el sector, especialmente en sus rutinas, afectando a la redacción pero, sobre todo, al diseño. En el año 2000 las imágenes reproducidas en papel eran las mismas que las que aparecían en el portal online (Caminos, Marín Murillo y Armentia Vizuete, 2006), pero este paradigma ha cambiado por completo

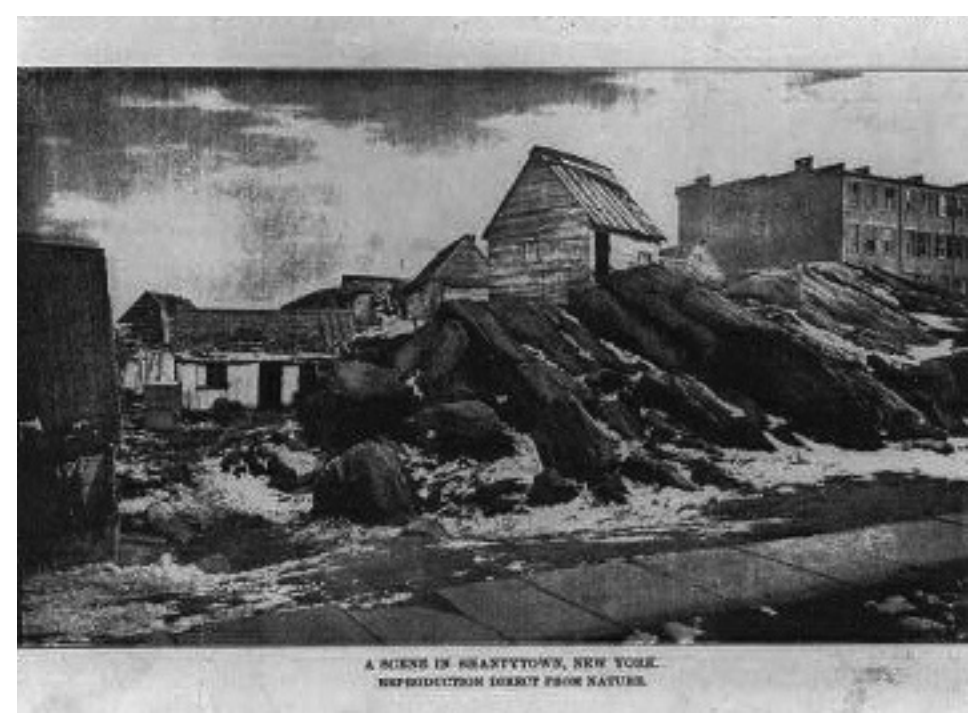
con el paso de los años (figura 5). 


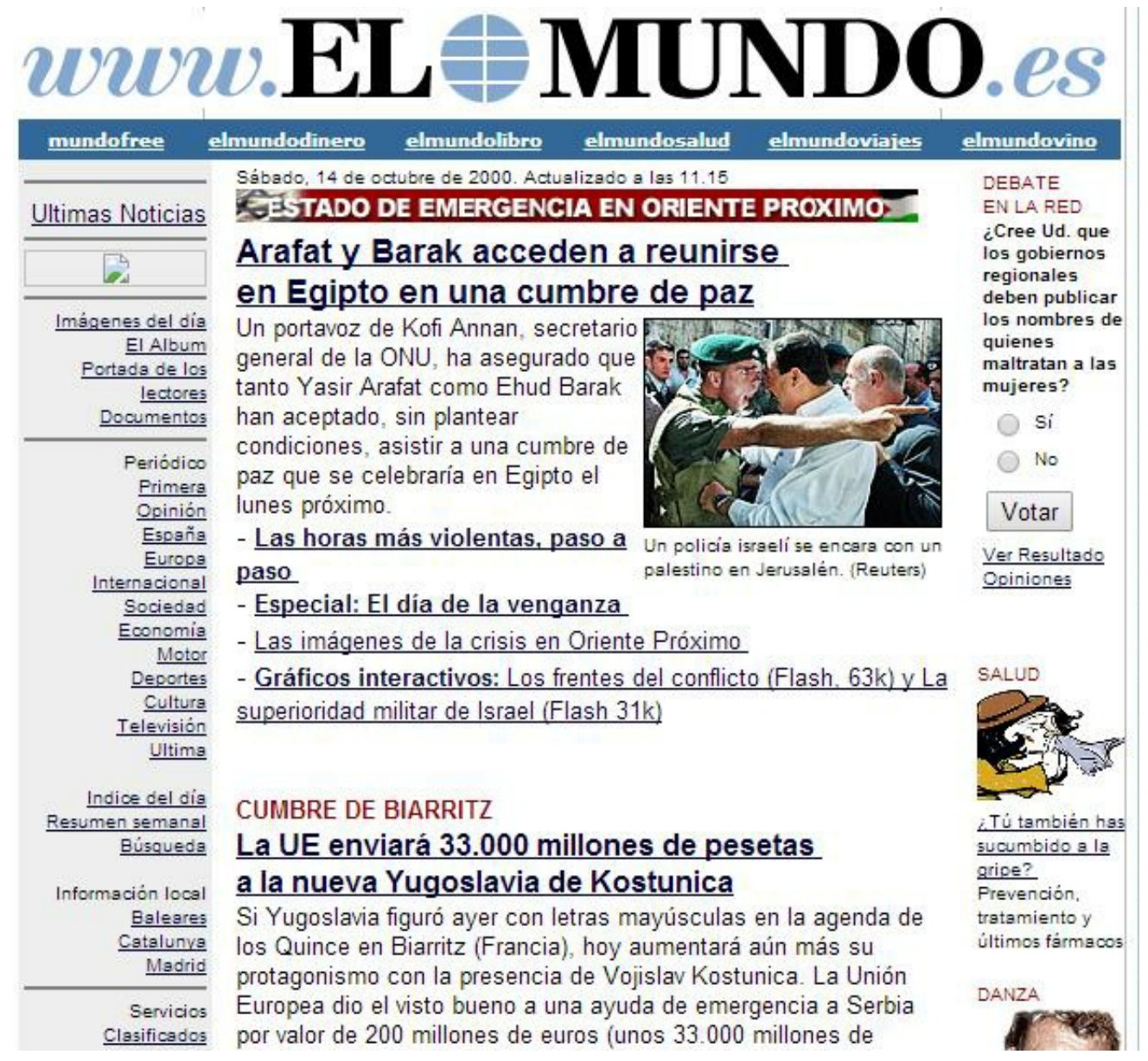

Figura 5. Página web del diario El Mundo del día 14 de octubre de 2000

Según señala López del Ramo (2010), la fotografía en la prensa digital es el elemento que ha experimentado el mayor cambio en comparación con su uso en la prensa de papel. Esta mutación ha acarreado para la fotografía una pérdida de importancia informativa en el sentido clásico del fotoperiodismo. Los medios online utilizan las imágenes pero lo hacen de una manera masiva y con una función meramente decorativa (figura 6).

\section{ELEMUNDO}

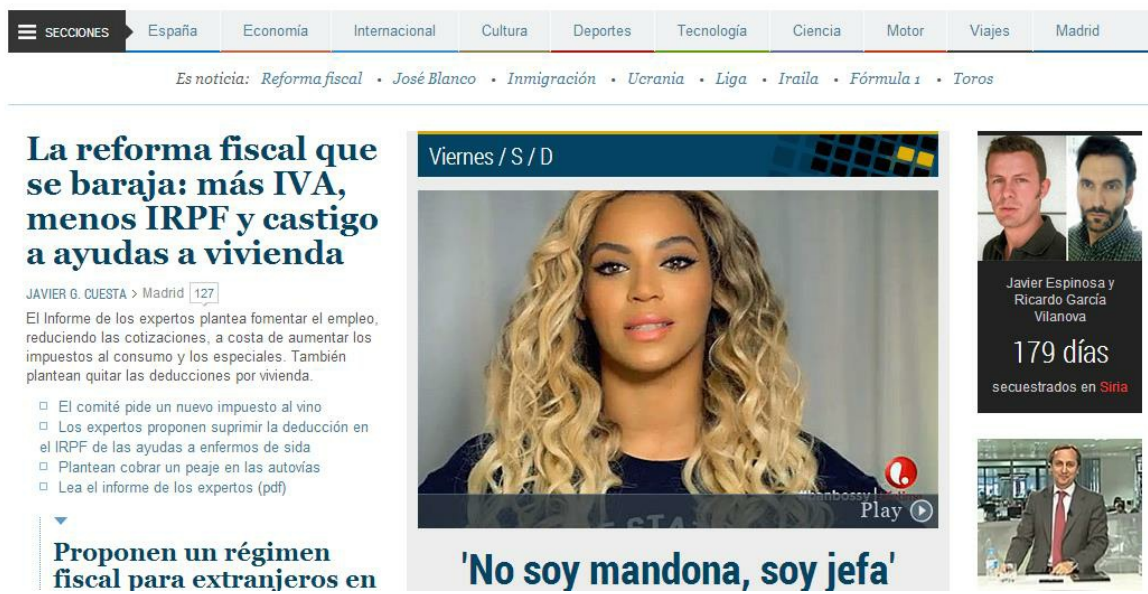

Figura 6. Página web del diario El Mundo el 14 de marzo de 2014

Este hecho se constata con la creación, por parte de los medios digitales, de galerías fotográficas. Para López Aguirre (2009), este tipo de recurso no siempre está ligado a un hecho informativo concreto sino que casi todos los diarios poseen galerías genéricas y heterogéneas. De hecho, éstas pueden ser incluso generadas por los lectores, de hecho el $58 \%$ de los diarios online estadounidenses soportan este tipo de recursos (Johnson ,2008).

Los investigadores Armentia Vizuete (2005), Caminos, Marín Murillo y Armentia Vizuete (2006), y Sánchez Vigil, 
Marcos Recio y Villegas Tovar (2007) coinciden en señalar que las galerías fotográficas de los medios digitales no siempre aportan claves para la comprensión total de un hecho noticioso debido a la falta de contexto y de asociación referencial entre las imágenes y las informaciones.

Las galerías fotográficas fueron uno de los cinco elementos presentes en los medios de comunicación online analizados por Mosconi, Porta y Ravarelli (2008). Los investigadores realizaron un estudio para comprobar cuál era el comportamiento de los usuarios con respecto a cinco acciones habituales en la interacción con la prensa online: acceder a una noticia (en formato textual, fotográfico o audiovisual), buscar el link en una sección concreta en la homepage, navegar a través de una galería fotográfica, leer una noticia en una página que incluye banners publicitarios y visionar un vídeo. Para ello, se realizó un test de usuarios a 30 participantes. Los usuarios debían entrar en las páginas de diversos periódicos italianos, previamente guardadas en un disco local, y realizar diversas tareas. La investigación concluyó que la indicación clara del número total de imágenes disponibles en las galerías es una información apreciada por los usuarios. Numerar las fotos y mostrar botones de 'siguiente' y 'anterior' con los que los usuarios puedan interactuar también son buenas prácticas a seguir para lograr una buena navegación. Las fotografías deben ser significativas y se debe evitar que todas ellas compartan el mismo subtítulo. Por último, se anima a evitar el uso del roll overdisplay (1), ya que puede no ser entendido correctamente.

\subsection{Fotoperiodismo}

El fotoperiodismo, tal y como lo entendemos hoy en día, tiene sus inicios en la Alemania de principios del siglo XIX. El espíritu liberal que trajo consigo la República de Weimar favoreció el florecimiento de las artes y las ciencias. En ese momento se inició la edad de oro del periodismo fotográfico y de su fórmula moderna. De las páginas de las revistas alemanas (principalmente del Berliner llustrierte Zeitung (figura 7) y el Münchner Illuestrierte Presse) empezaron a desaparecer los dibujos para dejar sitio a las fotografías que reflejaban la actualidad y que acompañaban a los textos. El cambio alcanzó incluso a la condición social de los fotógrafos, quienes provenían de la burguesía y la aristocracia. 


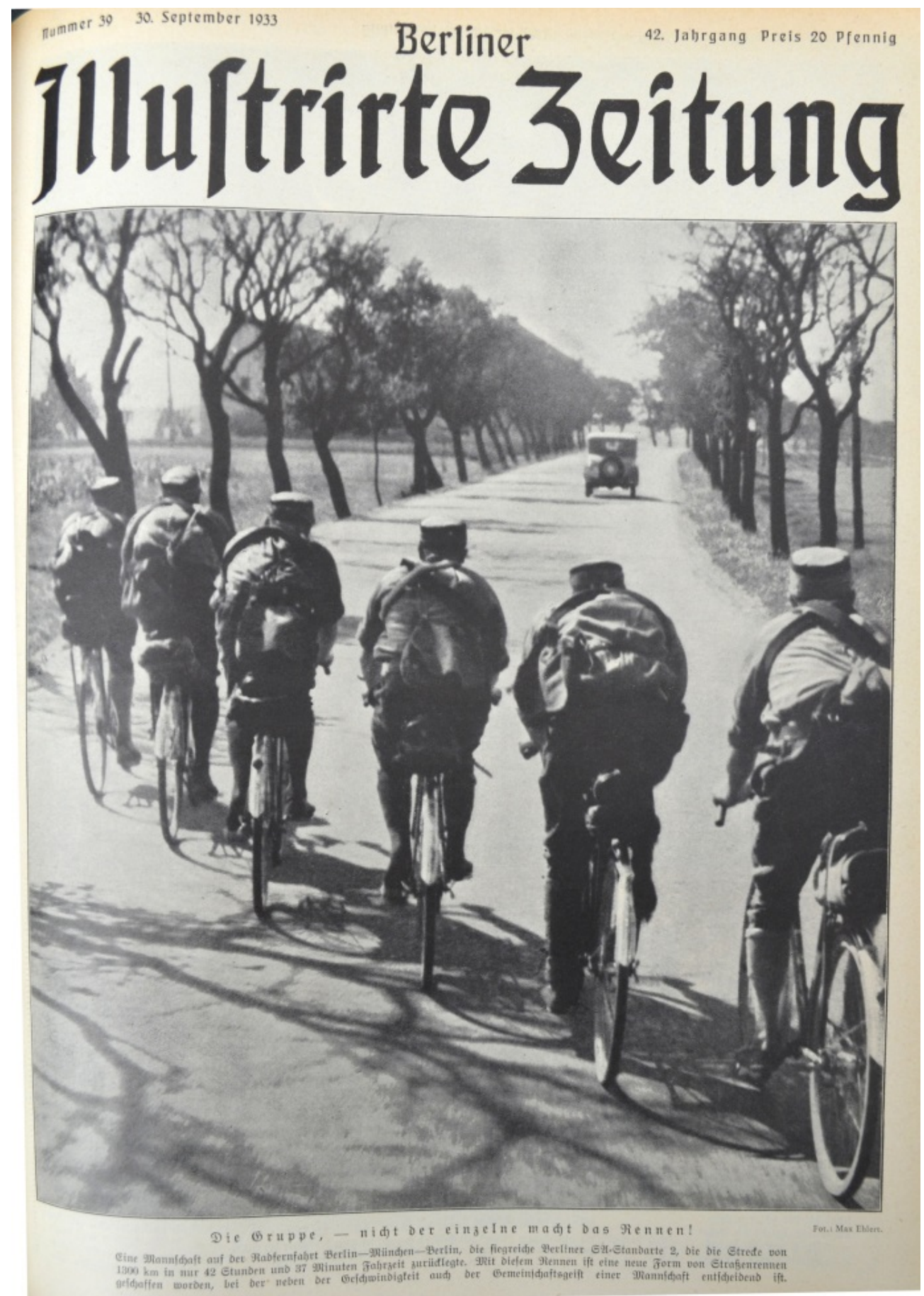

Figura 7. Portada del Berliner Illustrierte Zeitung del 30 de septiembre de 1933

De entre todos los fotoperiodistas, destacó la figura de Eric Salomon, que estuvo rodeado de otras grandes figuras como Felix H. Man, GermaineKrull, André Kertesz, Alfred Eisenstaedt, Moholy-Nagy y Martin Murcaszi. Con el ascenso de Hitler al poder, la mayoría de estos fotógrafos se marchó de Alemania para continuar ejerciendo. Algunos de ellos se fueron a trabajar a la revista Life (figura 8), que llegó a ser la más importante de su género en el mundo y un referente del fotoperiodismo. 


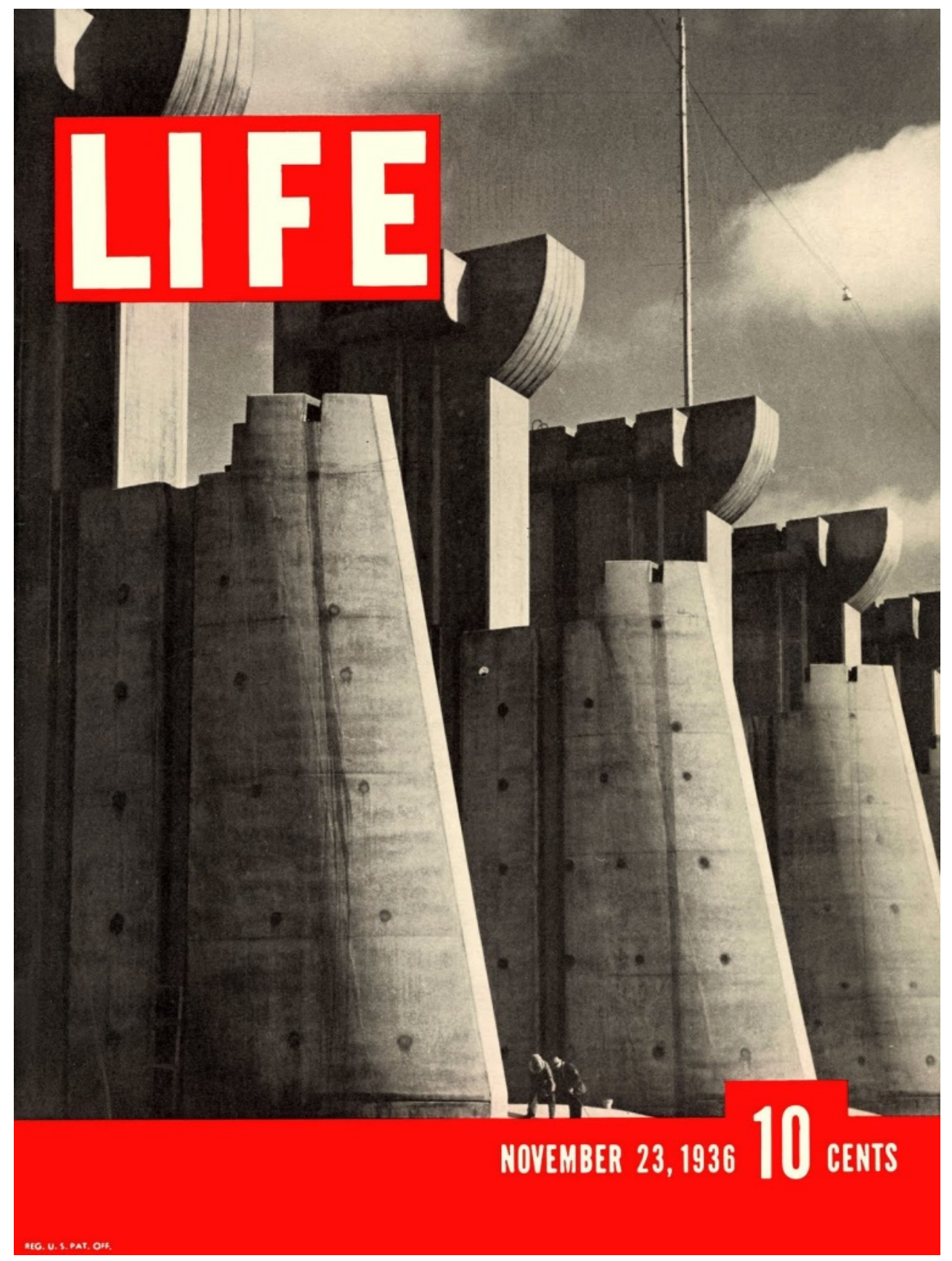

Figura 8. Primera portada de la revista Life del 23 de noviembre de 1936

En 1955, y fruto del gran momento por el que pasaba el fotoperiodismo, se creó el World Press Photo, el mayor y más prestigioso premio de fotografía en prensa del mundo. Además de otorgar los galardones a las mejores imágenes, esta organización sin ánimo de lucro también lucha por promover el fotoperiodismo y estimular la prensa fotográfica profesional en todo el mundo.

En la actualidad, la esencia del fotoperiodismo sigue siendo la misma que la de sus inicios en la Alemania de Weimar, si bien la digitalización ha cambiado la manera de presentar los contenidos al lector. Según se desprende del estudio que llevó a cabo Villa Montoya (2004), que analiza 311 imágenes de ediciones digitales de los diarios La Vanguardia, El País y EI Mundo, las emisoras de radio Cadena Ser, Onda Cero y COPE, y las cadenas de televisión Antena 3 y Telecinco, los criterios de inserción de imágenes en los portales de prensa online son poco flexibles, aunque el tratamiento que los medios hacen sobre las imágenes varía en función de su tipología. Es decir, en los portales web de los canales de televisión la imagen se utiliza en mayor cantidad de ocasiones que en aquellos sites pertenecientes a periódicos y emisoras de radio. El informe también destaca el cada vez más frecuente hábito de utilizar tecnología de frames (2), especialmente en las webs de canales de televisión. En cambio, en los portales de prensa se continúa optando por la fotografía como herramienta visual.

En 2012 el Poynter Institute llevó a cabo un estudio sobre tablets también basándose en la técnica del eye tracking(Quinn, 2012). Contaron con 36 participantes que acudieron a un test de usuarios. Durante la sesión de 
testeo debían navegar desde un iPad por portales de noticias creados para la ocasión. Se les presentaron tres prototipos con las mismas noticias pero con diferentes diseños (figura 9): traditional (con un diseño similar al de un periódico online), carousel (con un diseño basado en imágenes del mismo tamaño acompañadas de titulares) y flip board (con un diseño basado en grandes fotografías que destacaban únicamente algunas noticias). Además de descubrir que los usuarios preferían una distribución de los contenidos en forma de carousel, los investigadores concluyeron que los usuarios tienden a entrar en una pantalla a través de un elemento dominante, generalmente una fotografía.

\section{PROTOTYPE: Traditional}

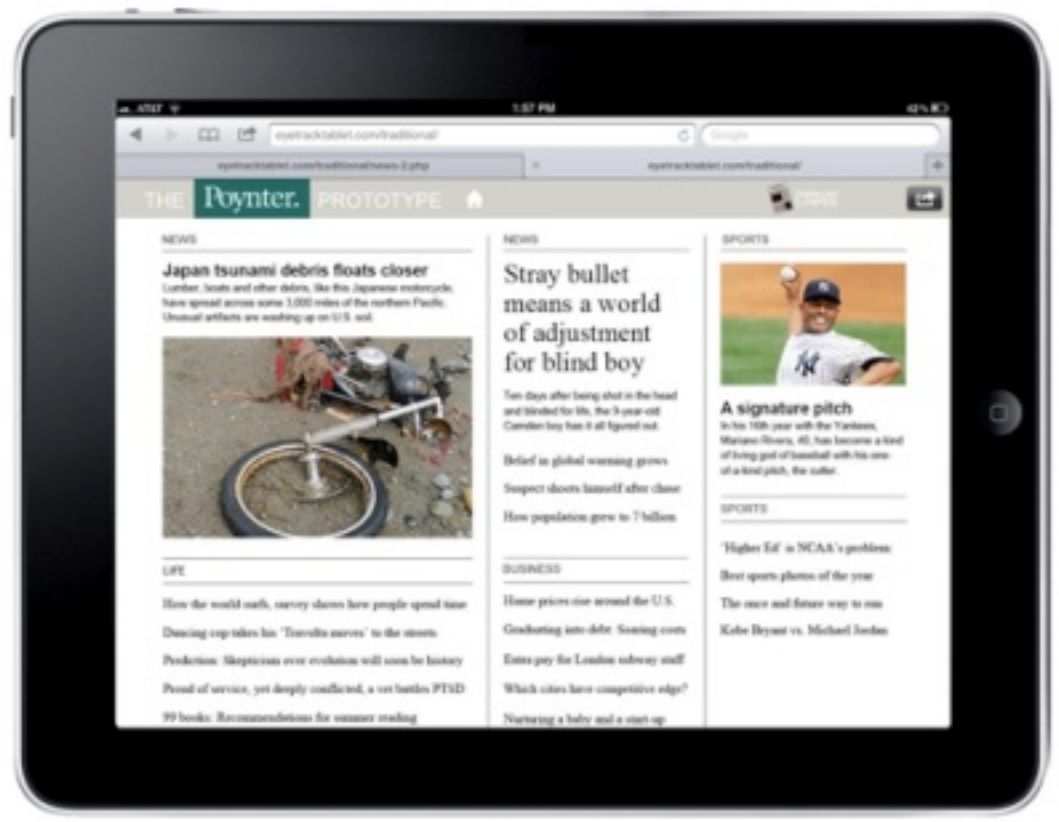

\section{PROTOTYPE: Carousel}

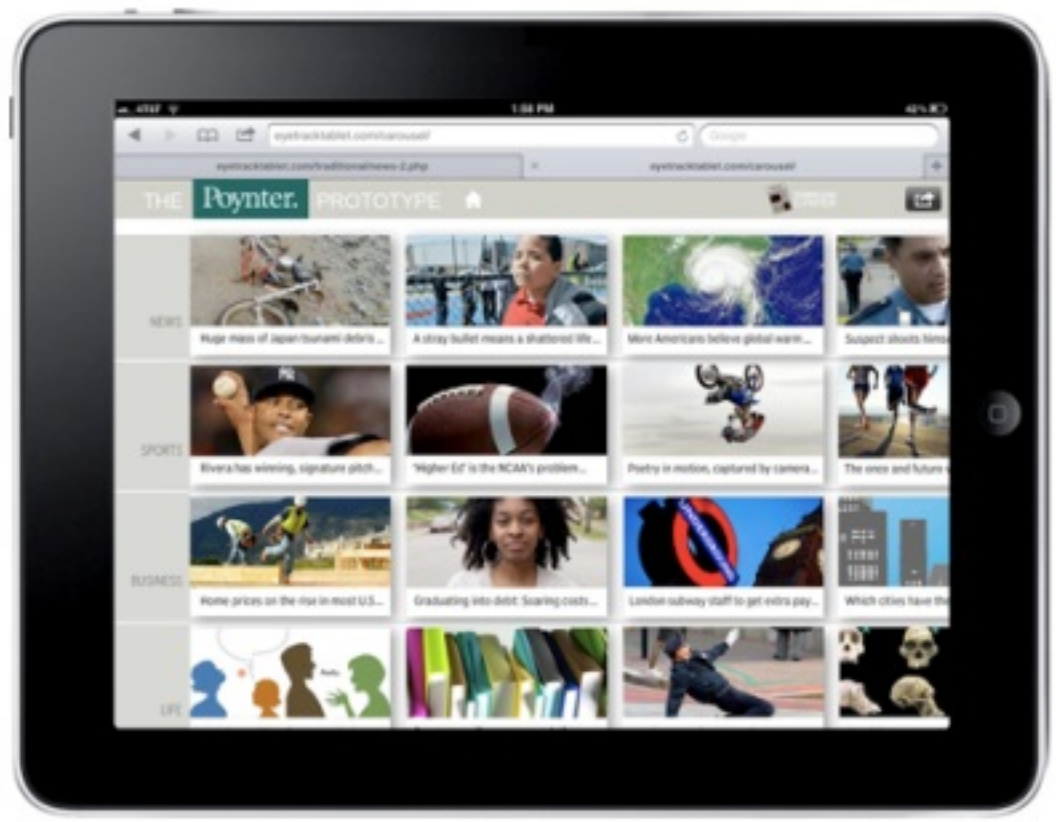

\section{PROTOTYPE: Flipboard}

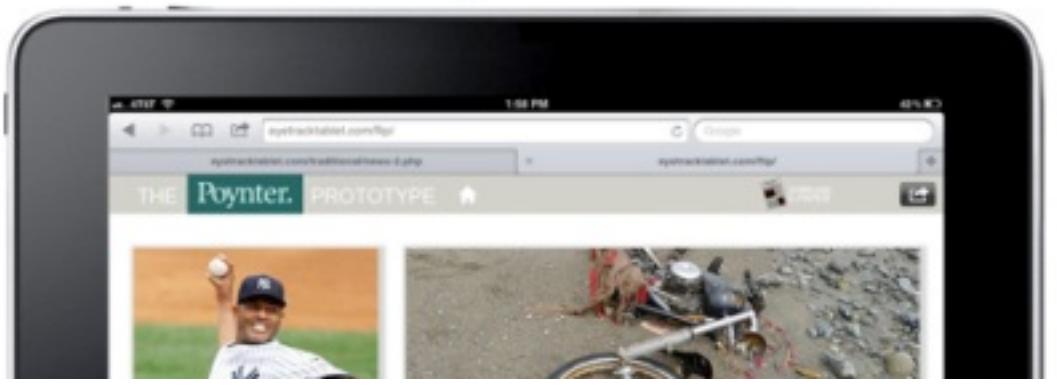




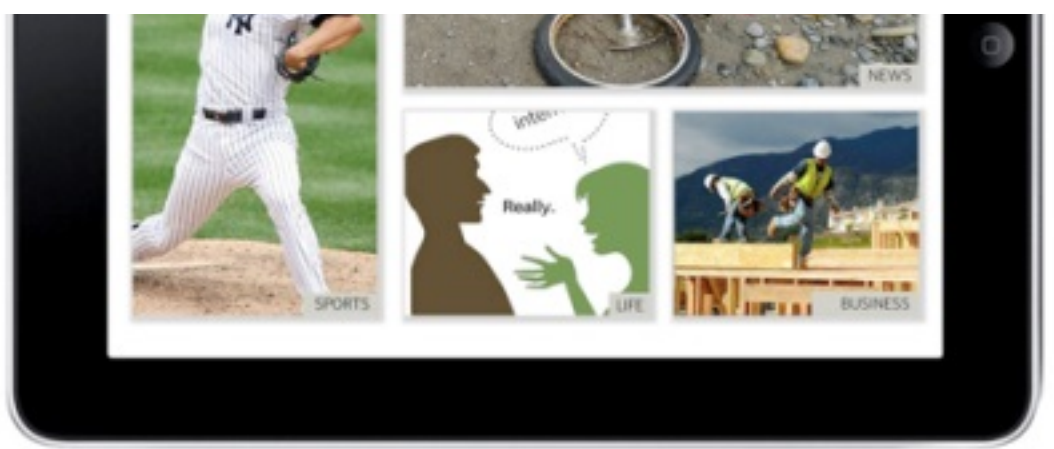

Figura 9. Los tres prototipos empleados en el estudio: traditional, carousel y flipboard. (Fuente: Quinn, 2012)

Sin embargo, la importancia de la fotografía no reside tanto en la tecnología de la que proviene sino en su contenido. Es aquí donde aparece uno de los dilemas clásicos del periodismo en general: ¿dónde se dibuja la delgada línea que separa una imagen con alta carga emocional de otra sensacionalista o que busque el morbo? Para Stephen Ferry (2013), fotoperiodista y documentalista, es una cuestión difícil y totalmente subjetiva. A pesar de ello, Ferry defiende que "las imágenes son realidades que deben producir emociones" aunque sin olvidar, aunque sea a nivel personal, dónde acaban los límites éticos.

\subsection{Infografías}

Las infografías y los gráficos están cada vez más presentes en los medios de comunicación. Para Valero Sancho (2001) una buena infografía debe contar con ocho características básicas: que dé significado a una información plena e independiente, que proporcione la información de actualidad suficiente, que permita comprender el suceso acontecido, que contenga la información escrita con formas tipográficas, que contenga elementos icónicos precisos, que pueda tener capacidad informativa suficiente y sobrada para tener entidad propia o que realice funciones de síntesis o complemento de la información redactada, que no contenga errores y que proporcione cierta sensación estética, aunque esta última no es imprescindible.

Por otra parte, Alberto Cairo (2012) establece dos filosofías de trabajo diferentes en la fase de creación y tratamiento de las infografías: estetizante y analítica. La primera se caracteriza por hacer presentaciones atractivas y divertidas en las que la integridad de los datos, la estructura de la presentación y la eficacia comunicativa no sean las preocupaciones primordiales. En la segunda, en cambio, se prioriza la funcionalidad ante el artificio visual sin dejar de lado el aspecto estético de la infografía. Para Cairo, que ha estudiado ampliamente las infografías, "el diseñador debe primero preocuparse por la legibilidad, la estructura, la narrativa, la claridad y la profundidad antes de pensar en el estilo o debe pensar en el estilo como una forma de reforzar la funcionalidad".

Pero no sólo la estructura de la propia infografía es importante para que el usuario la pueda comprender en toda su extensión. También se debe tener muy en cuenta su ubicación en el interior del artículo o de la página en cuestión. Holsanova, Holmberg y Holmqvist (2009) llevaron a cabo una investigación para estudiar el principio de la contigüidad espacial (spatialcontiguity) y la orientación a la lectura guiada o preestablecida (dual attentionalguidance). Para ello, realizaron un test de usuarios a 31 lectores habituales de un periódico sueco. Para el experimento se escogieron dos gráficos y se manipularon para obtener dos versiones de cada uno de ellos. Para el primer gráfico se creó una versión integrada, con el gráfico intercalado en el texto (figura 10), y otra separada, con el gráfico situado debajo del texto (figura 11). Para el segundo gráfico se creó una versión serial, con el orden de lectura establecido (figura 12), y otra radial, sin el orden de lectura establecido (figura 13). 
Figura 10. Versión del gráfico como objeto independiente del texto. (Fuente: Holsanova, Holmberg y Holmqvist, 2009)
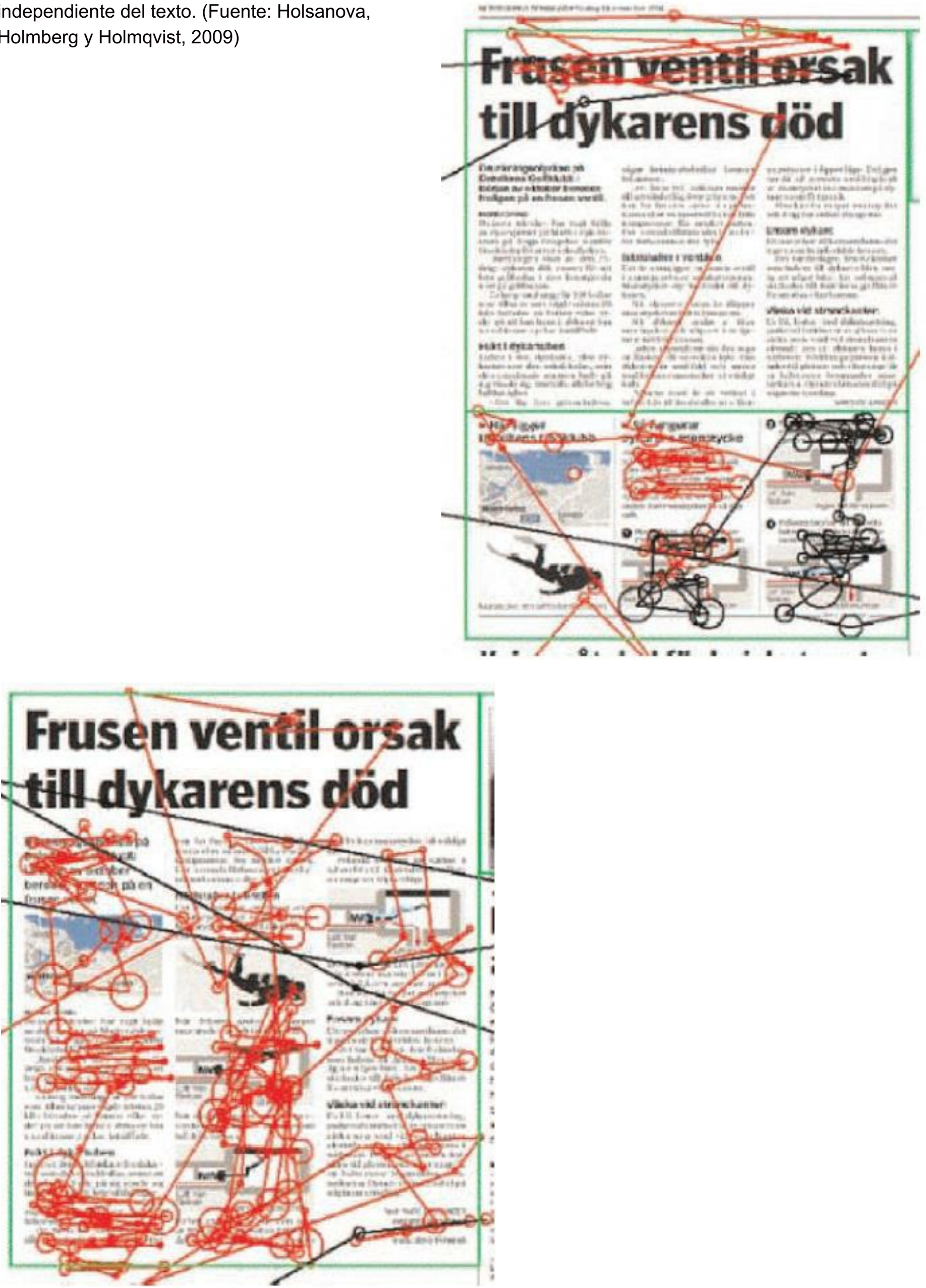

Figura 11. Versión del gráfico como objeto integrado en el texto.(Fuente: Holsanova, Holmberg y Holmqvist, 
2009)

Las conclusiones revelaron que la diferencia de disposición en el primer gráfico tenía un efecto significativo en el comportamiento de los usuarios: en el caso del gráfico separado, los usuarios no interactuaban entre el texto y el gráfico, trataban a este como una pieza independiente. En el caso del gráfico integrado, al haber menos espacio físico entre el texto y la información gráfica, los usuarios relacionaban con más facilidad la información de las dos fuentes.

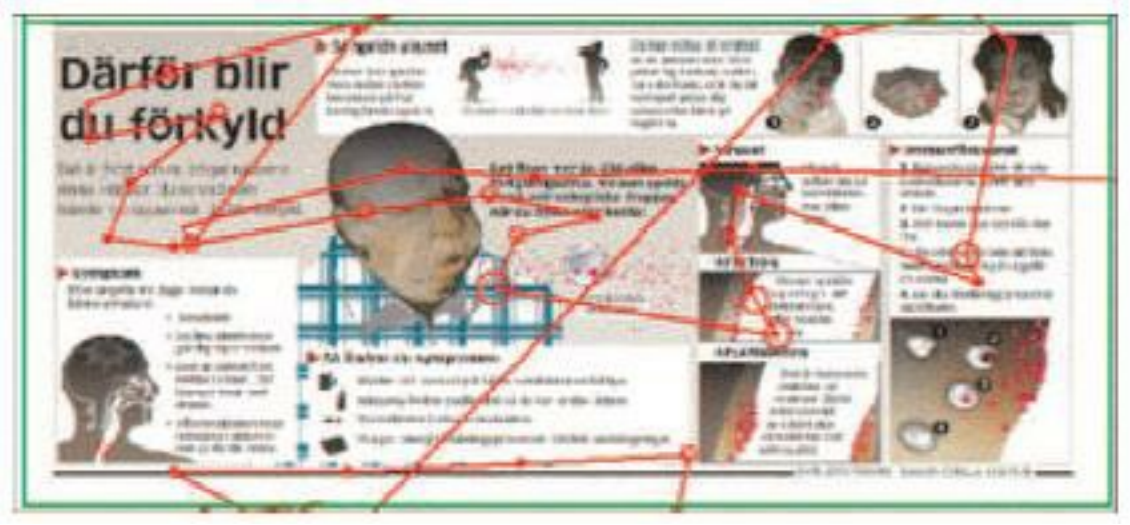

Figura 12. Versión del gráfico radial, con orden de lectura preestablecido.(Fuente: Holsanova, Holmberg y Holmqvist, 2009)

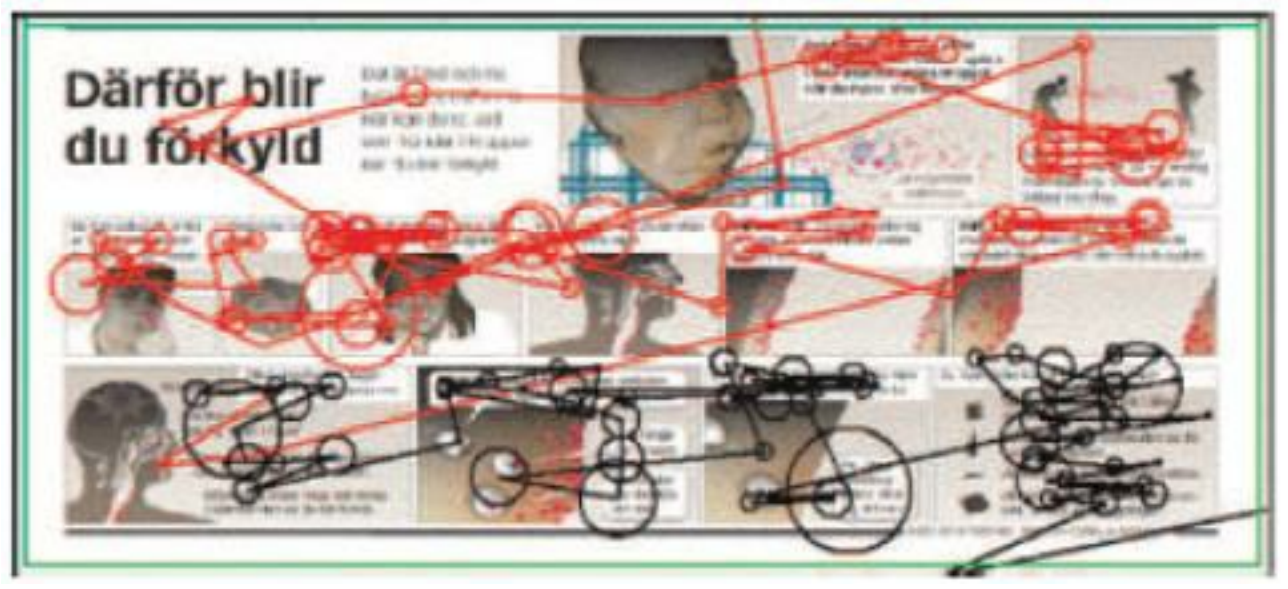

Figura 13. Versión del gráfico serial, sin orden de lectura preestablecido.(Fuente: Holsanova, Holmberg y Holmqvist, 2009)

En el segundo gráfico se apreció que la versión radial, sin indicaciones claras de dónde comenzar y cómo continuar consumiendo la información, no era efectiva si se quería llamar la atención de los lectores. Los usuarios debían hacer un esfuerzo añadido para establecer un punto de entrada y los pasos que llevaría a cabo para comprender la información. En cambio, la versión serial, con la información estructurada y un orden establecido, ayudó a llamar la atención de los usuarios y facilitó la comprensión y el procesamiento del contenido.

Dada la importancia y proliferación de las infografías en la prensa, la bibliografía sobre el tema es extensa. No vamos a detenernos más en ellas y damos paso a otros aspectos sobre la imagen.

\subsection{Fotografía de rostros}

El comportamiento de los usuarios ante la presencia de fotografías en las que aparecen rostros de personas ha sido estudiado con anterioridad. Destaca el ya citado estudio realizado por el PoynterInstitute, que en 2004 se ayudó de la técnica del eye trackingpara llevar a cabo un test de usuarios con 46 participantes (Outing, Ruel, 2004). Durante una hora los usuarios navegaron por diferentes portales web de noticias ficticios, creados por los propios investigadores. Los resultados apuntaron que las imágenes que contenían caras claras y nítidas recibían más fijaciones visuales en las páginas web. 
En 2012 este instituto llevó a caboel ya citado estudio sobre tabletstambién basándose en la técnica del eye tracking (Quinn, 2012). Entre otros aspectos, los investigadores concluyeron que los usuarios tienden a entrar en una pantalla a través de un elemento dominante, generalmente una fotografía, y que las fotografías y los vídeos en los que aparecen rostros llamaban altamente la atención a los usuarios.

Otro estudio, aún más reciente, constata la importancia de la fotografía de rostros. Guerini, Staiano y Albanese (2013) llevaron a cabo un estudio sobre imágenes y viralidad en la red social Google+. Entre otros resultados, los investigadores constataron que las imágenes que contenían rostros de personas recibían más votos y eran más comentadas que las demás.

\subsection{Fotografía, prensa y redes sociales}

Debido a su reciente aparición y a pesar de ser uno de los temas sobre los que más se ha investigado en los últimos años, hay una falta de consenso entre los expertos e investigadores sobre la definición de red social. Una de las más propagadas es la de Boyd y Ellison (2008, p. 211), para quienes la red social "es un servicio web que permite a los usuarios construir un perfil público o semipúblico en un sistema delimitado, articular una lista de otros usuarios con los que comparten una conexión y mirar su propia lista de conexiones y las de otros usuarios dentro del sistema". En España, el Instituto Nacional de Tecnologías de la Comunicación (INTECO, 2009 , p. 7) define las redes sociales como "los servicios prestados a través de Internet que permiten a los usuarios generar un perfil público en el que plasmar datos personales e información de uno mismo, disponiendo de herramientas que permiten interactuar con el resto de usuarios afines o no al perfil publicado".

Desde la aparición de My Space y Xing, en 2003, el fenómeno de las redes sociales en Internet no ha dejado de crecer. En apenas una década estas plataformas se han convertido en un punto de encuentro de nuestra sociedad, el ágora del siglo XXI. La red social Facebook, creada en 2004, contaba con 1 billón de usuarios registrados en octubre de 2012. El principal competidor de esta empresa es Google +, que en diciembre de 2012 contaba con unos 500 millones de usuarios registrados. Por su parte, Instagram tenía 150 millones de usuarios registrados en enero de 2014, Twitter alcanzaba los 200 millones de usuarios registrados en febrero de 2013 y Linkedln superaba los 277 millones de usuarios en abril del mismo año. Estos datos de las principales redes sociales occidentales pueden dar una idea aproximada del alcance y del arraigo que tienen este tipo de plataformas en la sociedad de nuestros días.

Los medios de comunicación no son ajenos al fenómeno de las redes sociales, aunque quizá por una pura cuestión de necesidad. Según Flores Vivar (2009), las empresas de medios de comunicación que quieran sobrevivir han de tener en cuenta las redes sociales. Los medios deben adaptarse a los cambios tecnológicos e incorporar dentro de sus estrategias los nuevos códigos de comunicación resultantes de la irrupción de estas plataformas. Flores Vivar (2009) recalca también la importancia de que los periodistas se familiaricen con las redes sociales, ya que estas son las herramientas con las que la audiencia se relaciona diariamente. Además, destaca el cambio conceptual con el que se enfrentan los medios de comunicación con presencia en estas plataformas: la transformación de la audiencia en comunidad. Es decir, la comunicación unidireccional entre emisor y audiencia pasa a ser una comunicación bidireccional entre emisor y comunidad. Mientras que la audiencia tradicional no tenía posibilidad de interactuar con otros receptores, los usuarios en las redes sociales están totalmente conectados, con lo que pueden interactuar entre sí.

Otros autores también coinciden al predecir que el futuro de los medios de comunicación pasa, irremediablemente, por internet y, más concretamente, por las redes sociales. Francis Pisani, en su participación en el libro de Briggs (2007), se muestra muy crítico con la poca capacidad de apreciación que han tenido los medios de comunicación para adaptarse con velocidad a la web y al nacimiento de estas nuevas plataformas. Por otra parte, Jarvis (2007) augura para 2020 un cambio radical en la figura del periodista, que pasará a actuar más como un organizador de información que como un productor de la misma.

En su adaptación a este nuevo entorno, los medios de comunicación deben tener en cuenta algunas consideraciones técnicas. Para Campos (2008), las redes sociales toman elementos característicos de los medios tradicionales a los que se les incorpora la interacción por parte de los usuarios. También precisa que su evolución va más encaminada hacia el medio audiovisual y virtual que a la prensa escrita y predice que la 
calidad de los contenidos que se viertan en estas plataformas se verá mermada por la cantidad de las mismas y por su poca profesionalización.

Noguera Vivo (2010) estableció una serie de afirmaciones tras realizar un estudio sobre los medios de comunicación españoles en Facebook. El investigador destacó la importancia de aprovechar la participación de los usuarios de manera real, es decir, contestando y atendiendo a sus comentarios. También criticó la falta de transversalidad de los contenidos creados por los medios de comunicación en las redes sociales, puesto que apenas enlazaban a contenido externo. Además, hizo especial hincapié en distinguir entre posibilidades de conectividad y la participación efectiva de las audiencias (distinción entre número de seguidores y seguidores activos que interactúan con cierta asiduidad o frecuencia).

Con la aparición y el auge de las redes sociales, la imagen cuenta con otro espacio en el que publicarse y darse a conocer, y a su vez generar viralidad y popularidad.

Guerini, Staiano y Albanese (2013) llevaron a cabo un estudio sobre imágenes y viralidad en redes sociales. La investigación determinó que las publicaciones con imágenes resultan ser mucho más virales, expandiendo así la posibilidad de que otros usuarios consulten la publicación. Para estudiar el fenómeno usaron la red social Google+, de donde reunieron una muestra de 289.434 publicaciones creadas por los 979 usuarios con más seguidores de esta red. Clasificaron las publicaciones en tres grupos: posts con imagen estática, posts con imagen dinámica y posts sólo textuales. Para estudiar la viralidad utilizaron tres métricas: Plusoners (número de +1), replies (número de comentarios) y reshares (número de usuarios que había compartido la publicación). Tras el análisis, concluyeron que las publicaciones con imágenes triplicaban la posibilidad de ser virales (considerando el número de shares) que aquellas en las que sólo había texto. Además, constataron que las imágenes divertidas o informativas tenían mayor probabilidad de ser compartidas mientras que las imágenes coloridas o que contenían rostros de personas eran más apreciadas (obteniendo así más plusoners o +1) y comentadas.

Khosla, Das Sarma y Hamid (2014) llevaron a cabo una investigación en la red social Flickr para determinar qué elementos hacían popular, entendiendo que la popularidad esté directamente relacionada con el número de visualizaciones que recibe una imagen. Para ello, los investigadores se centraron en el análisis del contenido de las imágenes y en el contexto social de un total de 2,3 millones de imágenes. Para analizar el contenido de las imágenes utilizaron varias técnicas automáticas llevadas a cabo por ordenador (histogramas de color, histogramas de degradados, texturas, etc.) mientras que para analizar el contexto social se basaron en el número de amigos que tenía la persona que subió la fotografía a la red social. Los investigadores concluyeron que las imágenes en las que predominaban los colores verdosos y azulados eran menos populares que aquellas en las que aparecían tonos rojizos (figura 14). La explicación vendría dada porque los colores más llamativos captan mayor atención por parte de los usuarios y es más fácil que visualicen ese tipo de fotografías. En cuanto a los objetos, se establecieron cuatro grupos en los que la popularidad iba de más a menos: imágenes con impacto positivo (mayoritariamente incluyen minifalda, maillot, bikini, sujetador, copa, perfume y revólver), imágenes con impacto positivo medio (suelen incluir guepardo, oso panda, básquet, llama, mariquita), imágenes con impacto negativo medio (con elementos como jabalí, carruaje, guacamole, catamarán y plato solar) e imágenes con impacto altamente negativo (con objetos como espátula, ordenador portátil, carrito de golf, desatascador y estufa). 


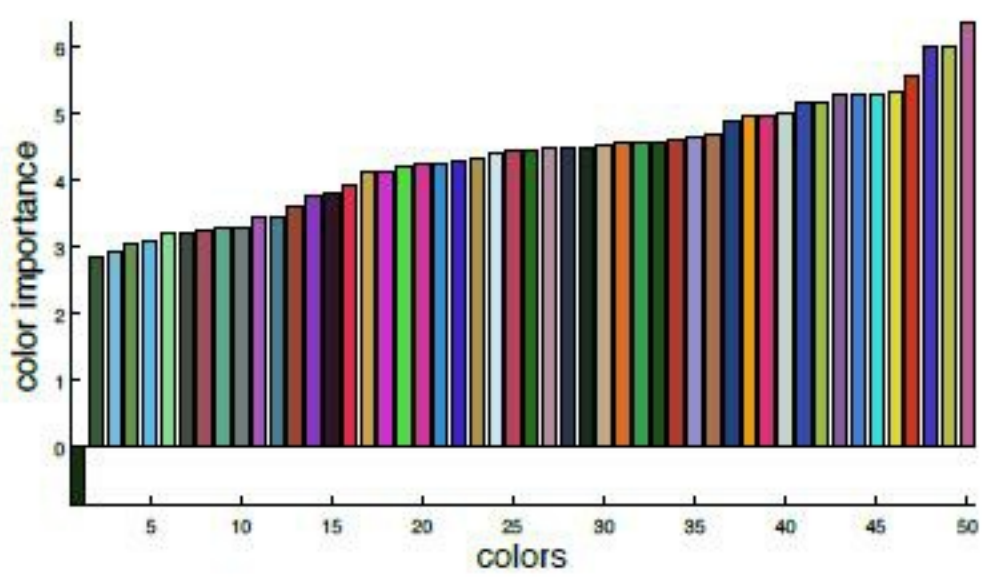

Figura 14. Los colores con tonos rojizos predominan en las imágenes más populares. (Fuente: Khosla, Das Sarma y Hamid, 2014)

Aparte de los estudios mencionados en este apartado, hay otros que han aplicado la tecnología de seguimiento de la mirada (eye tracking) para conocer el comportamiento visual de las personas cuando leen prensa. El siguiente apartado comenta los avances en esa línea.

\section{APLICACIÓN DE LA TÉCNICA DE EYE TRACKING A ESTUDIOS DE PRENSA ONLINE Y REDES SOCIALES}

\subsection{Estudios de eye tracking en prensa online}

Desde que el Instituto Poynter realizó los primeros estudios sobre los medios de comunicación online en los años 90, distintos investigadores han decidido aplicar la técnica del eye trackingpara analizar el comportamiento de los usuarios al interactuar con la prensa online. En los últimos años, las investigaciones alrededor de la prensa online se han centrado en temas tan diversos como la usabilidad de las interfaces de los medios digitales, el comportamiento de los lectores en los medios online y en su edición en papel, o en la publicidad en los periódicos digitales.

Michailidou, Harper y Bechhofe (2008) investigaron el comportamiento visual de los usuarios a la hora de navegar en interfaces de prensa online. Para ello analizaron 9 páginas web con la intención de determinar cómo el desorden visual de la página está relacionado con los patrones de comportamiento de navegación de los usuarios. Los resultados mostraron que los elementos salientes (que destacan) llaman antes la atención de los usuarios y que estos tienden a pasar más tiempo en el contenido principal de la página. El estudio enfatizó que el patrón de comportamiento visual común empieza en los elementos salientes de la página. A partir de ahí, la mirada de los usuarios sigue el siguiente camino: va al contenido principal, más tarde al titular, después a la columna de la derecha y de ahí a la de la izquierda para terminar en la zona del pie de página.

Con la intención de identificar la relación entre el comportamiento de lectura y la presentación del contenido, Leckner (2012)comparó el comportamiento de los lectores de prensa online con los lectores de prensa de papel. La investigación se basó en la revisión y el análisis de estudios empíricos, especialmente aquellos que empleaban la técnica del eye tracking. Los resultados mostraron que los elementos textuales, el tamaño y el emplazamiento son una guía relevante para ambos medios. Por otra parte, se concluyó que las imágenes no obtuvieron una mayor atención visual en el medio online. No obstante, y debido a la complejidad que entrañan los patrones y comportamientos de lectura, la investigación no pudo proporcionar una conclusión consistente que apuntara en una dirección clara.

El trabajo de Cantoni, Porta, Ricotti y Zanin (2013) partió con el propósito de investigar cuáles son las mejores estrategias para atraer la atención de los usuarios con el fin de reducir la banner blindness (3). Para ello estudiaron con tecnología eye tracking el comportamiento visual de 50 usuarios mientras estos veían diferentes páginas webs de periódicos online. Los resultados demostraron que el banner situado justo encima de la barra de navegación fue visto antes y más veces que los banners laterales, aunque durante menos tiempo que estos. 
Además, destacó que la duración media de la fijación fue superior en el banner de la izquierda (figura 15).

Figura 15. Framework de las páginas web de periódicos que se crearon para el experimento. En él se puede apreciar el posicionamiento de los diferentes banners. (Fuente: Cantoni, Porta, Ricotti y Zanin, 2013)

Con la intención de determinar el grado de importancia que los usuarios prestan a los titulares, a las fuentes y a los resúmenes que aparecen en el buscadorGoogle News, Rovira, Capdevila y Marcos (2014) llevaron a cabo un estudio sirviéndose de la técnica del eye tracking. Para determinar qué elemento captó más la atención de los usuarios, analizaron el tiempo que los 50 participantes del test emplearon en visionar los resultados de la búsqueda.

Los resultados determinaron que los usuarios prestaban más atención a las fuentes que a los resúmenes, mientras que no

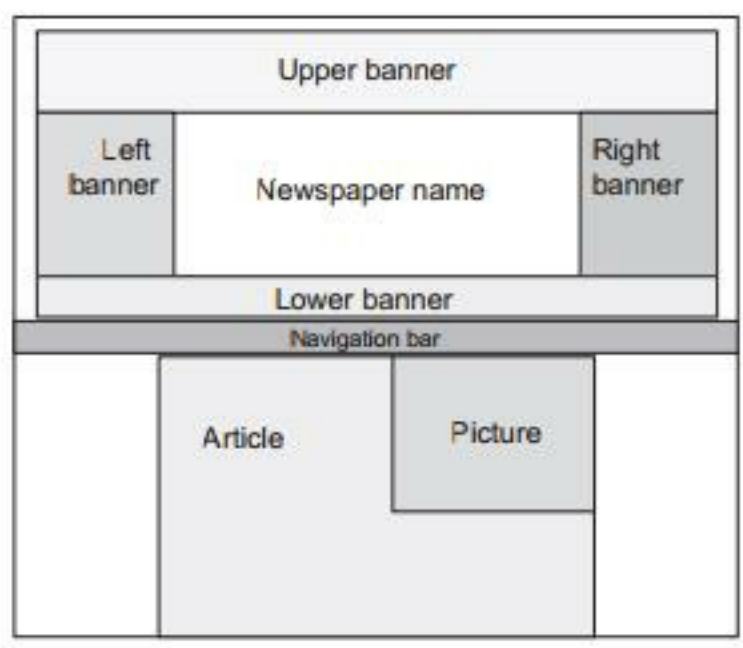
había diferencia significativa entre el tiempo que los usuarios dedicaban a visualizar las fuentes con el que empleaban en ver el título, de lo que se deduce que los usuarios sí tienen en cuenta la fuente de donde procede la notica que van a leer, contrariamente a lo que podría pensarse a priori.

\subsection{Estudios de eye tracking en Facebook}

El comportamiento de los usuarios en Facebook apenas ha sido estudiado a través de la técnica del eye tracker. La investigación de Boyd, Nugent, Donnelly, Sterritt y Bond (2012) es de las pocas que se han adentrado en el estudio del comportamiento de los usuarios en Facebook a través de esta tecnología.Para la realización del estudio,los investigadores llevaron a cabo un test de usuarios con 20 participantes, de los que 9 eran hombres y 11 mujeres con edades comprendidas entre los 22 y los 65 años. El test consistió en que los usuarios realizaran diversas tareas típicas de Facebook (actualizar el estado, enviar un mensaje y subir una foto) a través de una cuenta genérica. En el test, los usuarios debían interactuar por primera vez con la nueva versión del timeline de Facebook que salió a la luz sobre noviembre de 2011. La investigación concluyó que los participantes de mayor edad tenían más problemas que el resto para familiarizarse con el nuevo diseño y, de media, tardaron 20 segundos más en completar las tareas (figura 16). Los usuarios más jóvenes se divirtieron explorando las funcionalidades del nuevo timeline de la red social mientras que los usuarios más veteranos se sintieron preocupados por la posibilidad de cometer errores al tratar con una interfaz que no les resultaba familiar.

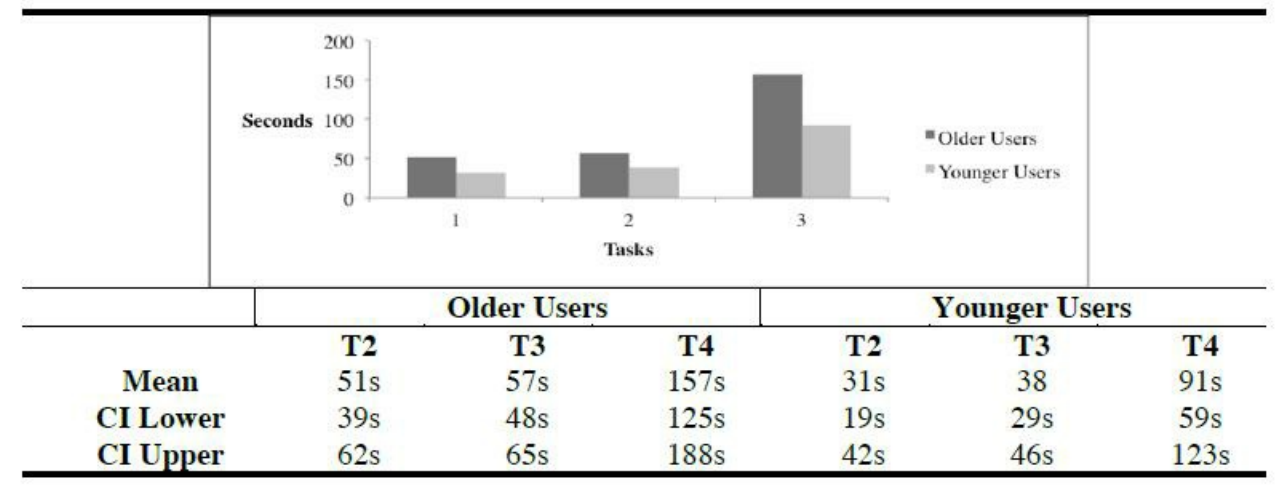

Figura 16. Los usuarios de mayor edad tardan más que los jóvenes en realizar las tareas. (Fuente: Boyd, Nugent, Donnelly y Bond, 2012)

\subsection{Eye tracking en estudios de prensa en Facebook}

Como se indicaba anteriormente, apenas existen estudios realizados con la técnica del eye tracker en Facebook. De hecho, el único que se ha podido localizar hasta el momento es el de Cárcamo, Marcos, Cladellas y Castelló (pendiente de publicación), quienesutilizaron este método parallevar a cabo una 
investigación que analiza el comportamiento de las personas en la lectura de los posts de prensa online que los medios de comunicación digitales cuelgan en su muro de Facebook. El estudio tiene como objetivo descubrir si la presencia o ausencia de imagen y el tamaño de esta influyen en la capacidad de atracción visual de una noticia, en el interés de los lectores por una noticia y en el número de lectores que escogen una noticia para seguir informándose. Para ello, se realizó un test de usuarios con 24 participantes. Semostró, a cada participante uno de los tres muros de Facebook preparados para el estudio. Cada muro conteníauna misma noticia tres veces y variaba solamente la presencia o ausencia de imagen junto al texto de la noticia, y elespacio que ocupaban texto e imagen. Una vez presentado el muro ante el usuario se le pedía que escogiera uno de los tres formatos de la noticia según sus preferencias. Las conclusiones del estudio fueron muy reveladoras: la mitad de los usuarios $(50 \%)$ clicó en el muro de Facebook que contenía la imagen más grande. Además, se demostró que los participantes se veían más fácilmente atraídos por la imagen grande (tardaban menos tiempo en fijar la mirada en la fotografía desde que se abría el muro de Facebook). La imagen grande también logró más tiempo de permanencia de la mirada sobre ella y fue seleccionada más veces, es decir, que los usuarios miraban antes, durante más tiempo y clicaban más las noticias con imágenes grandes que aquellas que contaban con una fotografía de menor tamaño o no tenían fotografía acompañando al texto.

\section{CONCLUSIONES}

La obligada adaptación de los medios de comunicación al mundo de las redes sociales y el cambio radical del papel de la fotografía en el mundo de la prensa son dos temáticas que, como se acaba de comprobar, han sido objeto de amplias investigaciones. No obstante, y a pesar de que existen estudios recientes como el de Cárcamo, Marcos, Cladellas y Castelló (pendiente de publicación)o el de Guerini, Staiano y Albanese (2013), que relacionan imágenes y redes sociales, hay un vacío claro de investigaciones que traten de unir o abordar estos dos temas al mismo tiempo.

Con este artículo damos inicio a una serie de investigaciones sobre la imagen de prensa en las redes sociales. En un futuro estudio pretendemos ofrecer resultados sobre la influencia que tienen las imágenes publicadas por los medios de comunicación online en el comportamiento de los usuarios, concretamente consideramos interesante conocer qué tipo de imágenes están utilizando los medios de comunicación en las noticias que publican en sus páginas de Facebook, y por otro lado estudiar cómo nos comportamos los usuarios de Facebook ante la presencia de noticias de actualidad en esta red social en función del tipo de fotografía que acompaña al texto de la noticia.

\section{REFERENCIAS BIBLIOGRÁFICAS}

ABAD, G.; LEÓN, C.:"La fotografía: entre la emoción y la información. Entrevista con Stephen Ferry”. Conservatorio 'Fotoperiodismo, violencia y cultura de paz en Colombia'. Universidad Andina Simón Bolívar, (2013)pp. 63-67.

Armentia-Vizuete, J.:"Los diarios digitales siguen buscando su propia identidad tras una década de existencia”. Estudios sobre el mensaje periodístico, n. 11,(2005) pp. 9-22.[En línea] [Consulta 6octubre 2014]. Disponible en <http://revistas.ucm.es/inf/11341629/articulos/ESMP0505110009A.PDF>

Beymer, D.; Ortom, P.; Russells, D.:"Aneye trackingstudy of howpicturesinfluence online Reading”. HumanComputerInteraction. Interact 2007, LNCS 4663, Part II, pp.456-460.

Boyd, D.; Ellison, N.: "Social network sites: Definition, history and scolarship". Journal of computer-mediated communication. 13,(2008) pp. 210-230.

Boyd, K.; Nugent, C.; Donnelly, M.; Sterritt, R.; Bond, R.: "A usability protocol for evaluating online social networks". Springer. Lecture Notes in Computer Science, (2012) pp. 222-225.

Briggs, M. (2007). Journalism 2.0. Austin (Texas): Knight Center of Texas University.

Cairo, A.; Rovira, C.:“Entrevista a Alberto Cairo sobre Infografía”. Hipertext.net, núm. 10, (2012). [En línea] [Consulta 7 junio]. Disponible en: <http://www.upf.edu/hipertextnet/entrevistas/entrevista_alberto_cairo.html> 
Caminos, J.; Marín-Murillo, F.; Armentia-Vizuete, J.:"El uso de la fotografía en los diarios digitales españoles". Comunicación y sociedad,v. XIX, n. 2,(2006) pp. 9-38.[En línea] [Consulta 6 octubre 2014]. Disponible en <http://www.unav.es/fcom/comunicacionysociedad/documentos/pdf/20090618122315.pdf>

Campos Freire, F.: "Las redes sociales trastocan los modelos de los medios de comunicación tradicionales". Revista latina de comunicación social, 63, (2008) pp. 277-286.

Cantoni, V.; Porta, M.; Ricotti, S.; Zanin, F.: "Banner Positioning in theMastheadArea of Online Newspapers: an eye tracking Study". International Conference on Computer Systems and Technologies,(2013) - Comp Sys Tech í 13.

Cárcamo, L.; Marcos, M.C.; Cladellas, R.; Castelló, A.: "Press photography for Facebook: Effects of images in three news' formats". Information Research. (pendiente de publicación).

Flores Vivar, JM.: "Nuevos modelos de comunicación, perfiles y tendencias en las redes sociales". Revista científica de educomunicación Comunicar, nº 33, v.XVII,(2009) 73-81.

Guerini, M.; Staiano, J.; Albanese, D.: "Exploring image virality in Google Plus". Department of information engineering and computer science, (2013) University of Trento.

Holsanova, J.;Holmberg, N.; Holmqvist, K.: "Reading information graphics: The role of spatial contiguity and dual attention alguidance". Applied cognitivi epsychology. 23,(2009)pp. 1215-1226.

INTECO. Estudio sobre la privacidad de los datos personales y la seguridad de la información en las redes sociales online. (2009).[En línea] [Consulta 6octubre 2014]. Disponible en:

$<$ http://inteco.es/file/vuinp2gnuminsjvyznpw2w>

Johnson, J.: The use of internet by America's largest newspapers”. (2008). The Bivings Group.

Khosla, A.;Das Sarma, A.; Hamid, R.:“What makes an image popular”. World Wide Web Conference'14, April 711, (2014) Seoul, Korea. ACM.

Leckner, S.: "Presentation factors affecting reading behaviour in readers of newspaper media: an eye-tracking perspective". (2012). [En línea][Consulta 6octubre 2014]. Disponible en:

<http://vcj.sagepub.com/content/11/2/163.short>

López-Aguirre, J.: "Estudio de servicios y productos ciberdocumentales en la prensa digital mexicana". Documentación en ciencias de la información, v. 32,(2009) pp. 93-132.

López-Del-Ramo, J.: "Configuración y contextualización de las galerías fotográficas en los diarios online. Propuesta de analítica aplicada”. El profesional de la información, v. 19, n. 5,(septiembre-octubre 2010) pp. 469475.

Michailidou, E.; Harper, S.;Bechhofe, S.: (2008) "Investigating Sighted Users Browsing Behaviour to Assist Web Accessibility". Proceedings of Tenth International ACM SIGACCESS. Conference on Computers and Accessibility, ASSETS 2008, pp. 121-128.

Mosconi, M.; Porta, M.; Ravarelli, A.: (2008) "On-line newspapers and multimedia content: an eye tracking studio". SIGDOC, (September 22-24 2008), Lisbon, Portugal.

Nielsen, J.; Pernice, K.: “Eyetracking web usability”. Chapter 6, Images. pp.196-226.

Noguera Vivo, JM.: "Redes sociales como paradigma periodístico. Medios españoles en Facebook". Revista latina de comunicación, (2010) pp. 176-186.

OUTING, S.; RUEL, L. "Eyetrack III: What We Saw When We Looked Through Their Eyes". (2004). [En línea] [Consulta 6 octubre 2014]. Disponible en: <http://www.poynter.org/uncategorized/24963/eyetrack-iii-what-newswebsites-look-like-through-readers-eyes> 
QUINN, S. "New Poynter Eyetrack research reveals how people read news on tablets. (2012). [En línea] [Consulta 6 octubre 2014]. Disponible en: <http://www.poynter.org/how-tos/newsgathering-storytelling/visualvoice/191875/new-poynter-eyetrack-research-reveals-how-people-read-news-on-tablets>

Rovira, C.; Capdevila, J.; Marcos, M.: "La importancia de las fuentes en la selección de artículos de prensa online: estudio de Google Noticias mediante eye-tracking."Investigación Bibliotecológica. 28:63, (2014)pp. 1528.

Sánchez-Vigil, J.; Marcos-Recio, J.; Villegas-Tovar, R.: "Los recursos fotográficos en los periódicos digitales. Valores de la fotografía digital". Ibersid, (2007)pp. 211-218. [En línea][Consulta 6octubre 2014]. Disponible en <http://ibersid.eu/ojs/index.php/ibersid/article/download/3298/3059>

Valero Sancho, JL.: "La infografía: Técnicas, análisis y usos periodísticos". Castellón: Publicaciones de la Universidad Jaime I (2001).

Villa Montoya, M.:"Funciones y cambios del fotoperiodismo en los medios online".Grup de recerca en imatge, so i síntesi de la Universitat Autònoma de Barcelona (GRISS).(2008). [En línea].[Consulta 6octubre 2014].

Disponible en: <http://www.ae-ic.org/santiago2008/contents/pdf/comunicaciones/170.pdf>

(1) Efecto que consiste en que la imagen cambia al pasar sobre ella el ratón

(2) Consiste en utilizar un fotograma del vídeo como imagen

(3) Fenómeno por el que los usuarios, de manera consciente o inconsciente, ignoran aquello que se asemeja a un banner o anuncio

\section{Breve semblanza de los autores:}

Víctor Arrazola es licenciado en Periodismo (Universitat Ramon Llull). Actualmente estudiante del Máster en Gestión de Contenidos Digitales (UB -UPF).

Mari-Carmen Marcos es Dra. en Documentación. Profesora en el Departamento de Comunicación de la Universitat Pompeu Fabra (UPF). Directora del Postgrado en Usabilidad y Experiencia de Usuario, Subdirectora del Máster en Documentación Digital, Co-directora del Máster en Buscadores (los tres UPF-IDEC), y profesora en el Máster en Gestión de Contenidos Digitales (UB -UPF). Su web: mcmarcos.com

* Este artículo se ha desarrollado a partir del trabajo de fin de máster de Víctor Arrazola, estudiante del Máster en Gestión de Contenidos Digitales, 2012-2015 (Universitat de Barcelona - Universitat Pompeu Fabra).

Ámbitos. Revista Internacional de Comunicación, n.27, año 2014, cuarto trimestre (invierno).

Recibido: 06/10/2014

Aprobado: 20/01/2015 